\title{
Hubungan Self Assessment-Peer Assessment dengan Nilai Kelulusan OSCE Mahasiswa Fakultas Kedokteran Unisba
}

\author{
Santun Bhekti Rahimah, ${ }^{1}$ Mia Kusmiati, ${ }^{2}$ Ermina Widyastuti ${ }^{3}$ \\ ${ }^{1}$ Departemen Farmakologi, ${ }^{2}$ Departemen Ilmu Biokimia, ${ }^{3}$ Departemen Ilmu Patologi Anatomi, \\ Fakultas Kedokteran, Universitas Islam Bandung
}

\begin{abstract}
Abstrak
Objective structured clinical examination (OSCE) adalah cara penilaian kompetensi klinik mahasiswa secara komprehensif dan konsisten serta dapat dijadikan media untuk meningkatkan hasil belajar. Feedback dapat dilakukan oleh mahasiswa itu sendiri (self assessment) maupun mahasiswa lain yang satu level (peer assessment). Self dan peer assessment diharapkan akan meningkatkan kemampuan mahasiswa dalam melihat tujuan pembelajaran, meningkatkan rasa percaya diri, kemampuan berpikir kritis, dan bertindak tepat dalam menghadapi ujian. Tujuan penelitian ini melihat hubungan self assessment dan peer assessment dengan nilai kelulusan OSCE mahasiswa tingkat dua dan empat FK Unisba tahun akademik 2012/2013. Nilai hasil ujian OSCE yang dipergunakan adalah pada periode Desember 2012-Juni 2013. Self dan peer assessment dilaksanakan setelah ujian OSCE. Self assessment dilakukan oleh mahasiswa itu sendiri, sedangkan peer assessment didapatkan dari lima orang mahasiswa lain yang pernah berada dalam satu kelompok dengan subjek. Hasil penelitian menunjukkan untuk mahasiswa tingkat dua terdapat korelasi bermakna self assessment dan peer assessment dengan nilai OSCE ( $\mathrm{p}<\mathrm{0}, 001)$, arah hubungan antara keduanya positif, serta kekuatan hubungan keduanya sedang $(\mathrm{R}=0,426)$. Pada mahasiswa tingkat empat terdapat korelasi bermakna antara self assessment dan nilai OSCE ( $<<0,001)$ dengan kekuatan hubungan keduanya sedang $(\mathrm{R}=0,451)$, serta terdapat korelasi yang bermakna antara penilaian peer assessment dan nilai OSCE. Simpulan, self assessment mempunyai korelasi positif terhadap nilai kelulusan OSCE pada mahasiswa tingkat dua dan tingkat empat, sedangkan peer assessment mempunyai korelasi positif dengan nilai kelulusan OSCE hanya pada mahasiswa tingkat dua. Self assessment mempunyai korelasi positif dengan peer assessment pada mahasiswa tingkat dua dan tingkat empat FK Unisba tahun akademik 2012/2013.
\end{abstract}

Kata kunci: OSCE, peer assessment, self assessment

\section{Relation between Self Assessment-Peer Assessment and OSCE's Results from Medical Students of Unisba}

\begin{abstract}
Objective structured clinical examination (OSCE) is a tools to assess students clinical competency comprehensively and consistently. It can also used as medium to improve the learning process. Feedback for student performance can be done trough self-assessment or peer assessment done by other students. Self and peer assessment are expected to enhance the ability of students to see the purpose of learning, improve self-confidence, the ability to think critically and act right in an examination. The aim of this study was to find the relationship between self assessment and peer assessment of the OSCE final mark of second and fourth grade student at Medical Faculty, Bandung Islamic University academic year 2012/2013. The OSCE mark used were taken from December 2012June 2013, while the self and peer assessment carried out after the OSCE finished. Self assessment were done by students themselves, while peer assessment obtained from five persons which have been in one group with subject. Results showed that for second grade student showed there was significant correlation between self-assessment and peer assessment and OSCE's mark value (p<0.001) with the direction of the relationship was positive and had moderate strength $(\mathrm{R}=0.426)$. Fourth grade students showed significant correlation only between self-assessment and OSCE's mark value $(\mathrm{p}<0.001)$ with moderate strength $(\mathrm{R}=0.451)$. There was no significant relation between the assessment of peer assessment and OSCE's mark value. In clonclusion, self assessment correlated positively to OSCE's mark value for second and fourth grade students. Peer assessment correlated positively to the passing scores for second grade student. Self assessment had a positive correlation to peer assessment for second and fourth grade medical students.
\end{abstract}

Key words: OSCE, peer assessment, self assessment

Korespondensi: Santun Bhekti Rahimah. Departemen Farmakologi, Fakultas Kedokteran, Universitas Islam Bandung.

E-mail: santunbr94@gmail.com 


\section{Pendahuluan}

Pendidikan kedokteran pada saat ini sudah menggunakan Kurikulum Berbasis Kompetensi (KBK) yang sesuai dengan KIPDI III. Perubahan paradigma dalam proses pendidikan kedokteran ini tentu saja membutuhkan dukungan dan kesiapan dari berbagai pihak, baik dari pihak institusi sebagai pelaksana, mahasiswa sebagai sasarannya, dan stake holder sebagai pengguna lulusan fakultas kedokteran ini. ${ }^{1,2}$ Salah satu hal yang sangat berpengaruh dalam proses akademik pendidikan adalah sistem evaluasi dan juga assessment (penilaian hasil belajar). Assessment dalam perubahan kurikulum ini secara ideal seharusnya bersifat komprehensif, memiliki parameter penilaian yang jelas dan objektif, serta menghasilkan output penilaian yang dapat dipertanggungjawabkan. ${ }^{3,4}$ Sangat diharapkan metode assessment yang digunakan mampu mengoptimalkan kapabilitas mahasiswa dengan cara menimbulkan motivasi dan arahan untuk proses pembelajaran selanjutnya, serta secara tidak langsung melindungi masyarakat dengan mengidentifikasi praktisi yang tidak kompeten. ${ }^{5}$ Secara garis besarnya, pendidikan kedokteran dilakukan dalam dua tahap, yaitu tahap Program Pendidikan Sarjana Kedokteran (PPSK) dan Program Pendidikan Profesi Dokter ( $\left.\mathrm{P}_{3} \mathrm{D}\right)$.

Penilaian hasil proses belajar di fakultas kedokteran pada tahap PPSK dilakukan dalam beberapa tahap, yaitu pada tahap student objective oral case analysis (SOOCA), objective structured clinical examination (OSCE), dan multiple discipline examination (MDE). Objective structured clinical examination (OSCE) ialah cara penilaian kompetensi klinik mahasiswa yang dinilai secara komprehensif dan juga konsistensi dari suatu rangkaian tindakan yang terstruktur dengan penekanan terhadap objektivitas prosesnya. ${ }^{6}$ Pada akhir tiap sesi setelah pelaksanaan OSCE, dilakukan feedback bagi mahasiswa yang merupakan proses integratif dengan kegiatan OSCE itu sendiri. Feedback dapat merupakan masukan berharga untuk meningkatkan proses belajar maupun pembelajaran dan secara signifikan terbukti meningkatkan performa kompetensi mahasiswa. ${ }^{7-9}$

Feedback tersebut dapat dilaksanakan oleh para penguji maupun mahasiswa itu sendiri, baik penilaian diri sendiri (self assessment) maupun penilaian dari mahasiswa lain yang berada satu level dengan mahasiswa tersebut (peer assessment).6,7 Self assessment dapat membantu para mahasiswa untuk mengenali kelemahan dan kekurangan masing-masing dalam upaya mencapai tujuan pembelajaran dan dapat meningkatkan rasa tanggung jawab mahasiswa dalam upaya melewati setiap tahap dalam OSCE. Keadaan ini juga mendorong mahasiswa untuk terus memperbaiki diri dan meningkatkan kemampuan pada keterampilan klinisnya. Akan tetapi, menilai diri sendiri itu adalah hal yang tidak mudah yang sering kali subjektif karena dipengaruhi oleh karakter diri kita sendiri, begitu pula dalam OSCE. ${ }^{6}$

Peer assessment juga perlu dikembangkan sebagai suatu metode assessment dikarenakan menitikberatkan terhadap penilaian kognitif, performa klinis, dan juga aspek interpersonal. Penelitian oleh Dannefer dkk. ${ }^{7}$ dinyatakan bahwa peer assessment mampu menilai domain lain di samping penilaian kognitif, yaitu nilai-nilai humanistik, relationship, serta interpersonal. Metode peer assessment secara keseluruhan merupakan metode yang reliabel dan valid walaupun terjadi secara alamiah dan tidak memberikan informasi atau nilai tertentu yang dapat diprediksi seperti umumnya parameter penilaian. Sangat diharapkan self assessment serta peer assessment ini akan meningkatkan kemampuan mahasiswa untuk melihat tujuan objektif dari pembelajaran, serta meningkatkan rasa percaya diri mereka, kemampuan berpikir kritis, dan bertindak sesuai keterampilan klinis yang berguna bagi kehidupannya kelak sebagai seorang dokter. ${ }^{6,9}$

Fakultas Kedokteran (FK) Universitas Islam Bandung (Unisba) adalah fakultas kedokteran yang sejak awal berdirinya sudah berkomitmen untuk menjalankan pendidikan menggunakan metode Problem Base Learning (PBL). Melihat sejarahnya, hampir delapan tahun FK Unisba melaksanakan ujian OSCE sebagai salah satu metode assessment pada mahasiswa yang rutin dilakukan pada semua mata kuliah Biomedical System Program (BMP) atau modul sistem di tahap PPSK. Kelulusan dari OSCE merupakan salah satu prasyarat untuk mahasiswa dalam penentuan kelulusan modul sistem atau dengan kata lain apabila mahasiswa tidak lulus OSCE pada suatu modul sistem maka dapat dipastikan mahasiswa tersebut tidak dapat lulus pada mata kuliah tersebut. Mahasiswa pada tingkat pertama 
belum dilakukan penilaian OSCE, sedangkan pada mahasiswa tingkat 2 (dua), 3 (tiga), dan 4 (empat) telah melaksanakan ujian OSCE pada semua modul sistem. Mahasiswa tingkat profesi atau klinik pada tahun 2013 mulai mengikuti ujian untuk komprehensif OSCE $\mathrm{P}_{3} \mathrm{D}$ dan mulai Februari 2013 harus siap untuk menghadapi OSCE UKDI. Berdasar atas hal-hal tersebut, peneliti tertarik untuk melihat pengaruh self assessment dan juga peer assessment terhadap kelulusan OSCE mahasiswa tingkat 2 (dua) dan 4 (empat) FK Unisba. Mahasiswa tingkat 3 (tiga) tidak diikutsertakan dalam penelitian ini karena waktu pelaksanaan OSCE tingkat 3 (tiga) tidak sesuai dengan waktu penelitian ini.

Penelitian ini dilaksanakan untuk menilai hubungan self assessment dan peer assessment dengan nilai kelulusan OSCE pada mahasiswa tingkat 2 (dua) dan 4 (empat) FK Unisba.

\section{Metode}

Penelitian ini merupakan penelitian analitik cross sectional dengan penentuan penilaian peer assessment secara random sampling. Bahan penelitian ini adalah format pernyataan kesediaan mengikuti penelitian ini, format self assessment, dan format peer assessment.

Subjek penelitian ini adalah mahasiswa tingkat 2 (dua) dan juga tingkat 4 (empat)pada tahap PPSK di Fakultas Kedokteran Unisba tahun akademik 2012/2013. Mahasiswa yang dapat melakukan self assessment tersebut harus sesuai dengan kriteria inklusi: tercatat secara administratif sebagai mahasiswa di tingkat dua dan tingkat empat pada tahap PPSK di Fakultas Kedokteran Unisba tahun akademik 2012/2013, aktif mengikuti $>80 \%$ kegiatan bimbingan skill atau skill laboratory untuk modul sistem pada tahun berjalan, mengikuti latihan OSCE sebelum pelaksanaan OSCE pada modul sistem yang akan diujikan, mengisi lembaran pernyataan kesediaannya untuk mengikuti penelitian ini, dan mengisi kuesioner dengan lengkap. Mahasiswa harus memenuhi kriteria inklusi tambahan untuk penilaian secara peer assessment, yaitu pernah berada dalam satu kelompok bimbingan skill laboratory dengan mahasiswa yang akan dinilai. Penelitian ini menggunakan sampel mahasiswa tingkat dua sebanyak 102 orang dan tingkat empat berjumlah 57 orang pada tahap PPSK di FK Unisba tahun akademik
2012/2013 yang berjumlah 124 orang.

Variabel dependen penelitian ini self student assessment dan juga peer student assessment, sedangkan variabel independennya kelulusan OSCE. Self student assessment adalah penilaian mahasiswa tingkat dua dan empat secara terpisah terhadap kemampuan dirinya atau self reflection yang menggambarkan kompetensi dirinya dalam menghadapi suatu pembelajaran dan ujian. Peer student assessment adalah penilaian mahasiswa tingkat dua dan empat secara terpisah terhadap mahasiswa lain yang berada satu level dengan dirinya terhadap kemampuan temannya atau kompetensi profesionalnya dalam menghadapi suatu pembelajaran dan juga ujian. Penilaian itu meliputi beberapa komponen penilaian, kognitif, relationship, serta juga nilai-nilai interpersonal dan humanistik. Objective structured clinical examination ialah cara penilaian kompetensi klinik mahasiswa dalam mengikuti suatu sistem pembelajaran, dalam hal ini dinilai dari OSCE system pada tahun berjalan. ${ }^{10,11}$

Kelulusan OSCE berdasar atas hasil penilaian nilai skor (actual mark) yang didapat mahasiswa ketika melaksanakan setiap station dalam ujian OSCE dan penilaian global rating mahasiswa.

Self assessment questionnaire yang dipakai merupakan modifikasi dari questionnaire yang dipergunakan oleh Harold F. O’Neil, Jr. (1996) yang berisi 20 item pertanyaan. Questionnaire ini mengalami modifikasi sehingga dilakukan uji validitas dan reliabilitas menggunakan Metode Pearson Corelation untuk melihat keakuratan setiap item pertanyaan. Hasil uji validitas dan reliabilitas dengan Metode Pearson Corelation memperlihatkan bahwa dari 25 item soal yang diujicobakan, empat di antaranya tidak valid sehingga sisanya terdapat 21 pertanyaan yang valid. Item pertanyaan yang tidak valid adalah pertanyaan nomor 1, 6, 14, dan 19. Sesuai dengan questionnaire Harold F. O’Neil, Jr. maka jumlah item pertanyaan yang akan digunakan adalah 20 soal sehingga pertanyaan nomor 23 juga dihapuskan disebabkan nilai korelasinya paling kecil bila dibanding dengan pertanyaan yang lain sehingga hasil akhirnya terdapat 20 pertanyaan pada modified self assessment questionnaire yang valid dan reliabel yang akan dipergunakan pada penelitian ini.

Hasil pengisian selfassessment questionnaire selanjutnya dikelompokkan menjadi 3 (tiga) kategori, yaitu kategori buruk: $\mathrm{x} \leq 26$, cukup/ sedang: $26<x<53$, dan baik: $x \geq 53$. Keterangan: 
$\mathrm{x}=$ nilai self assessment questionnaire, nilai maksimal 80.

Peer assessment questionnaire yang dipakai adalah modifikasi dari peer assessment protocol (PAP) yang digunakan oleh Elaine F. Dannefer dalam penelitiannya yang merupakan bagian dari comprehensive assessment dan didesain untuk dapat menilai kompetensi profesional pada mahasiswa fakultas kedokteran pada tahap sarjana kedokteran. ${ }^{7}$ Jumlah pertanyaan dalam questionnaire Elaine F. Dannefer berjumlah 15 pertanyaan. Pada penelitian ini Modifieed PAP Questionnaire yang berisi 20 pertanyaan perlu diuji kembali validitas dan reliabilitasnya untuk melihat keakuratan setiap item pertanyaan.

Hasil uji validitas dan reliabilitas memakai Metode Pearson Corelation itu memperlihatkan bahwa dari 20 item soal yang diujicobakan, 4 (empat) di antaranya tidak valid sehingga sisanya terdapat 16 pertanyaan yang valid. Item pertanyaan yang tidak valid adalah pertanyaan nomor 5, 6, 13, dan nomor 20. Sesuai dengan questionare Elaine F. Dannefer maka jumlah item pertanyaan yang akan digunakan adalah 15 soal sehingga pertanyaan nomor 18 juga dihapuskan karena nilai korelasinya paling kecil dibanding dengan pertanyaan yang lain. Hasil akhirnya terdapat 15 pertanyaan pada modified $P A P$ questionnaire yang valid dan reliabel yang akan digunakan pada penelitian ini.

Hasil berdasar atas pengisian peer assessment questionnaire selanjutnya akan dikelompokkan menjadi tiga kategori, yaitu kategori buruk: $x \leq 25$, kategori cukup atau sedang: $25<x<5$, dan kategori baik: $x \geq 50$, keterangan: $x=$ nilai peer assessment questionare, nilai maksimal adalah 75 .

Objective structured clinical examination ialah penilaian hasil belajar yang dilaksanakan untuk menilai proses skill laboratory mahasiswa yang dilakukan mulai tingkat dua sampai tingkat empat di tahap PPSK. Pada tahap profesi atau $\mathrm{P}_{3} \mathrm{D}$ ujian OSCE komprehensif dilaksanakan pada tahun 2013 untuk mahasiswa angkatan 2007 karena angkatan ini merupakan angkatan pertama di FK Unisba yang akan mengikuti UKDI OSCE Nasional pada tahun 2013 sehingga mahasiswa pada tahap profesi belum dapat dilibatkan dalam penelitian.

Mahasiswa tingkat 1 (satu) belum mengikuti OSCE karena mereka belum pernah mengikuti kegiatan skill laboratory, sedangkan semua mahasiswa tingkat selanjutnya pada setiap tahunnya diwajibkan mengikuti OSCE sebagai berikut: mahasiswa tingkat 2 (dua) mengikuti OSCE sistem reproduksi, sistem endokrin, dan sistemmetabolismesertasistemneurobehaviour, mahasiswa tingkat tiga mengikuti OSCE sistem dermatomuskuloskeletal, sistem kardiovaskular dan sistem hematologi, sedangkan mahasiswa tingkat 4 (empat) akan mengikuti OSCE sistem respirasi, sistem gastrointestinal, sistem genitourinari, dan sistem tropical medicine.

Sehari sebelum diadakan pelaksanaan OSCE mahasiswa diharuskan mengikuti dahulu latihan OSCE supaya mereka dapat melakukan latihan lagi dan sekaligus melakukan refleksi mengenai kesiapan mereka untuk menghadapi OSCE pada keesokan harinya. Pada saat pelaksanaan OSCE, mahasiswa dibagi dalam beberapa station yang jumlahnyaharus disesuaikan dengan kompetensi yang akan dinilai. Dalam pelaksanaan OSCE mahasiswa dibagi dalam beberapa kloter dan jumlah kloternya disesuaikan dengan jumlah station yang dilaksanakan.

Setiap station menghabiskan waktu 10 menit dengan pembagian satu menit untuk membaca soal dan 9 menit untuk pelaksanaan sehingga apabila dilakukan 10 station maka diperlukan waktu untuk satu kloter mahasiswa adalah 100 menit atau 1 jam 40 menit. Pada tahap akhir pelaksanaannya dilakukan feedback mengenai pelaksanaan OSCE. Nilai OSCE untuk mahasiswa tingkat dua diambil pada OSCE reproduksi dan mahasiswa tingkat empat pada OSCE gabungan sistem respirasi dan gastrointestinal.

Alur penelitian ini adalah sebagai berikut: mahasiswa tingkat dua dan tingkat empat FK Unisba tahun akademik 2012/2013 terlebih dahulu harus sudah menyelesaikan bimbingan skill laboratory pada setiap sistem yang sedang berjalan. Pada satu sistem waktu bimbingan yang diperlukan kurang lebih 7-8 minggu. Setelah itu, mahasiswa disosialisasikan dahulu mengenai self assessment dan peer assessment yang bertujuan agar setiap mahasiswa mengerti filosofi kegiatan ini serta memudahkan dalam proses pelaksanaannya. Mahasiswa diharapkan mengerti bahwa penilaian atau masukan yang dia berikan adalah suatu kritik yang membangun dengan tujuan yang sama agar meningkatkan kemampuan mereka dalam menghadapi ujian dan proses pembelajaran selanjutnya. Sebelum pelaksanaan OSCE dilakukan latihan OSCE yang merupakan suatu kesatuan dalam pelaksanaan OSCE yang bertujuan meningkatkan kesiapan 
semua mahasiswa sebelum pelaksanaan OSCE sesungguhnya sekaligus agar mahasiswa dapat melakukan refleksi mengenai kemampuan yang selama ini telah mereka miliki.

OSCE pada setiap sistem dilakukan memakai prosedur rutin OSCE yang dilakukan di FK Unisba. Penilaian OSCE dilaksanakan dengan criterion reference dan skor yang dipergunakan berskala 0-1-2, inadequate, correct sampai adequate. Selain itu, penilaian OSCE juga dinilai berdasar atas global rating yang merupakan penilaian performa mahasiswa itu secara utuh sehingga apabila skor aktualnya sudah memadai, akan tetapi global rating-nya tidak lulus maka mahasiswa dinyatakan tidak lulus.

Pada akhir OSCE mahasiswa melaksanakan pengisian self assessment questionnaire dan peer assessment questionnaire. Self assessment questionnaire diisi oleh mahasiswa itu sendiri, sedangkan peer assessment questionnaire setiap mahasiswa akan mengisi 5 questionnaire untuk menilai 5 temannya yang berada pada satu kelas pada saat kegiatan skill laboratory. Pemilihan mahasiswa untuk penilaian peer assessment ini dilakukan secara random agar didapat hasil yang lebih akurat. Hasil penelitian selanjutnya dinilai menggunakan analisis data atau statistik. Pada akhirnya, nilai questionnaire ini dikaitkan dengan nilai kelulusan OSCE.

Pengisian questionnaire dilaksanakan secara mandiri oleh semua mahasiswa yang sebelumnya dibacakan instruksi pengisian oleh pembimbing. Analisis statistik menggunakan Pearson Product Moment dan Rank Spearman untuk melihat korelasi self assessment dan peer assessment dengan kelulusan OSCE. Data self assessment dan peer assessment lalu diolah menggunakan program excel, sedangkan bagi para mahasiswa yang melaksanakan peer assessment ditentukan menggunakan tabel random.

Penelitian ini dilakukan di kampus FK Unisba Jalan Hariangbanga No. 2 Bandung periode Desember 2012-Juni 2013. Permintaan subjek untuk mengisi questionnaire itu memerlukan persetujuan dari pihak yang akan dimintai datanya, oleh karena itu diperlukan informed consent dari mahasiswa sebelum pengisian data. Informed consent dapat dilakukan secara langsung karena mahasiswa tingkat dua dan empat usianya sudah di atas 18 tahun sehingga sudah cukup dewasa secara hukum untuk menandatangani langsung suatu pernyataan. Penelitian ini juga menjaga kerahasiaan pada saaat penentuan peer assessment untuk menjaga objektivitas sehingga pemilihan peer dilakukan secara random agar semua orang mempunyai kesempatan yang sama untuk dapat menilai mahasiswa lain, tidak berdasar atas kedekatan atau hubungan keluarga. Selain itu, pengisisan data peer assessment tidak membubuhkan nama mahasiswa yang menilai agar kerahasiaan data tetap terjaga untuk dapat menjaga kebebasan setiap mahasiswa dalam memberikan kritik atau masukan yang membangun untuk mahasiswa lain.

\section{Hasil}

Mahasiswa tingkat dua yang datanya sudah diambil dan memenuhi kriteria inkusi jumlahnya 102 orang, sedangkan tingkat empat berjumlah 57 orang.

Berdasar Tabel 1 terlihat bahwa pada kedua kelompok mahasiswa tidak terdapat yang hasil penilaian self assessment-nya masuk kategori buruk, sedangkan yang masuk kategori cukup hanya pada sebagian kecil. Sebagian besar hasil penilaian self assessment mahasiswa termasuk kategori baik.

Penilaian peer assessment untuk seorang mahasiswa dilakukan oleh lima orang mahasiswa yang pernah sekelompok pada saat bimbingan skill laboratory sehingga mereka lebih mengenal rekan sekelompoknya dibanding dengan teman lain yang tidak pernah dalam satu kelompok. Dari Tabel 2 terlihat bahwa hasil penilaian peer

Tabel 1 Hasil Penilaian Self Assessment Mahasiswa Tingkat Dua dan Tingkat Empat FK Unisba Tahun Akademik 2012/2013

\begin{tabular}{lcc}
\hline Kategori Peer & $\begin{array}{c}\text { Mahasiswa Tingkat Dua } \\
\mathbf{n = 1 0 2}\end{array}$ & $\begin{array}{c}\text { Mahasiswa Tingkat Empat } \\
\mathbf{n}=\mathbf{5 7}\end{array}$ \\
\hline Buruk & 0 & 0 \\
Cukup & 7 & 2 \\
Baik & 95 & 55 \\
\hline
\end{tabular}


Tabel 2 Hasil Penilaian Peer Assessment Mahasiswa Tingkat Dua dan Tingkat Empat FK Unisba Tahun Akademik 2012/2013

\begin{tabular}{lcc}
\hline Kategori Peer & $\begin{array}{c}\text { Mahasiswa Tingkat Dua } \\
\mathbf{n = 1 0 2}\end{array}$ & $\begin{array}{c}\text { Mahasiswa Tingkat Empat } \\
\mathbf{n}=\mathbf{5 7}\end{array}$ \\
\hline Buruk & 0 & 0 \\
Cukup & 13 & 3 \\
Baik & 89 & 54 \\
\hline
\end{tabular}

assessment untuk setiap kelompok mahasiswa baik tingkat dua maupun tingkat empat tidak ada yang masuk kategori buruk. Sebagian besar masuk kategori baik dan sebagian kecil masuk kategori cukup.

Berdasar atas Tabel 3 dapat dilihat bahwa terdapat mahasiswa yang mempunyai nilai self assessment sempurna, tetapi tidak ada nilai peer assessment yang mencapai nilai sempurna. Data yang didapat dari hasil self assessment dan peer assessment questionnaire serta nilai OSCE, kemudian dinilai apakah data tersebut berdistribusi normal atau tidak menggunakan Uji One-sample Kolmogorov-Smirnov. Hasil yang didapat ternyata nilai OSCE mahasiswa tingkat empat tidak terdistribusi normal sehingga uji statistik yang digunakan adalah nonparametrik dengan menggunakan uji Spearman.

Berdasar atas Uji Spearman terlihat bahwa terdapat korelasi yang bermakna self assessment dengan nilai OSCE $(\mathrm{p}<0,001)$. Arah hubungan antara keduanya adalah positif, hal ini berarti kenaikan penilaian self assessment akan diikuti pula dengan kenaikan nilai OSCE. Kekuatan hubungan keduanya adalah sedang $(\mathrm{R}=0,451)$. Tidak terdapat korelasi yang bermakna antara penilaian peer assessment dan nilai OSCE.

Uji Pearson memperlihatkan bahwa terdapat korelasi yang bermakna self assessment dengan peer assessment $(\mathrm{p}<0,001)$. Arah hubungan antara keduanya adalah positif, artinya kenaikan penilaian self assessment akan diikuti pula dengan kenaikan peer assessment. Kekuatan hubungan keduanya adalah sedang $(\mathrm{R}=0,478)$.

Dari Tabel 4 terlihat mahasiswa mempunyai nilai selfassessment sempurna, akan tetapi tidak ada nilai peer assessment-nya yang mencapai nilai sempurna. Data yang didapat dari hasil self assessment dan peer assessment questionnaire serta nilai OSCE, kemudian dinilai apakah data tersebut berdistribusi normal atau tidak mempergunakan Uji One-sample KolmogorovSmirnov. Hasil yang didapat ternyata seluruh data terdistribusi normal maka uji statistik yang dipakai adalah parametrik menggunakan Uji Pearson.

Uji Pearson juga menggambarkan bahwa terdapat korelasi yang bermakna self assessment dan juga peer assessment dengan nilai OSCE $(\mathrm{p}<\mathrm{O}, \mathrm{O01})$. Arah hubungan antara keduanya adalah positif, artinya kenaikan penilaian self assessment akan diikuti pula dengan kenaikan nilai OSCE. Kekuatan hubungan keduanya adalah sedang $(\mathrm{R}=0,426)$.

Hasil uji tersebut diatas juga menggambarkan korelasi yang bermakna antara self assessment dan peer assessment $(\mathrm{p}=0,05)$. Arah hubungan antara keduanya adalah positif, artinya kenaikan penilaian self assessment akan diikuti pula dengan kenaikan peer assessment. Kekuatan hubungan keduanya sangat lemah $(\mathrm{R}=0,164)$.

\section{Pembahasan}

Self assessment merupakan bentuk keterlibatan mahasiswa dalam upaya mengidentifikasi kriteria atau standar untuk diterapkan dalam belajar dan membuat keputusan mengenai pencapaian kriteria atau standar tersebut. ${ }^{13}$ Pada intinya mahasiswa diharapkan dapat mengetahui apa

Tabel 3 Karakteristik Nilai Self Assessment, Peer Assessment, dan OSCE Mahasiswa Tingkat Empat FK Unisba Tahun Akademik 2012/2013

\begin{tabular}{lccccc}
\hline Variabel & $\mathbf{n = 5 7}$ & Minimum & Maksimum & Mean & Std. Deviation \\
\hline Self assessment & 57 & 49 & 80 & 64,1228 & 7,32173 \\
Peer assessment & 57 & 37 & 71 & 58,71 & 4,80031 \\
Nilai OSCE & 57 & 57 & 57,8 & 91,38 & 5,1451 \\
\hline
\end{tabular}


Tabel 4 Karakteristik Nilai Self Assessment, Peer Assessment, dan OSCE Mahasiswa Tingkat Dua FK Unisba Tahun Akademik 2012/2013

\begin{tabular}{lccccc}
\hline Variabel & n=102 & Minimum & Maksimum & Mean & Std. Deviation \\
\hline Selfassessment & 102 & 44 & 80 & 66,2843 & 8,6772 \\
Peer assessment & 102 & 47 & 69 & 56,9044 & 4,3466 \\
Nilai OSCE & 102 & 44,31 & 93,99 & 78,9016 & 7,5619 \\
\hline
\end{tabular}

yang sebenarnya dia ketahui dan yang tidak dia ketahui dalam proses pembelajarannya. Dengan kata lain, self assessment ialah proses tanggung jawab mahasiswa dalam menilai dirinya sendiri.

Hasil penelitian self assessment mahasiswa tingkat dua dan tingkat empat FK Unisba pada tahun akademik 2012/2013 menunjukkan bahwa sebagian besar mahasiswa mempunyai nilai self assessment yang baik, sedangkan sebagian kecil cukup, dan tidakadayang memperolehnilaiburuk. Hal ini merupakan keadaan yang baik karena dengan self assessment yang baik mahasiswa diharapkan mampu meningkatkan kemampuan merefleksikan diri, menilai, mengkritisi proses dan juga hasil belajar, membantu mahasiswa untuk membenahi diri, serta menentukan stategi apa yang akan dipergunakan untuk memperbaiki proses dan hasil belajar. ${ }^{12}$ Nilai self assessment yang baik juga menunjukkan bahwa mahasiswa mempunyai penilaian yang baik terhadap dirinya sendiri dan diharapkan dengan penilaian diri yang baik akan meningkatkan rasa percaya diri serta motivasi belajar yang baik pula.

Penilaian lain yang juga diamati pada penelitian ini adalah peer assessment. Peer assessment mampu menilai profesionalisme, komunitas dengan tim perawatan kesehatan, pembelajaran yang berbasis praktik, dan juga improvement pembelajaran. Peer assessment merupakan penilaian seorang mahasiswa oleh mahasiswa lain dalam satu level baik penilaian formatif sebagai feedback review maupun penilaian sumatif untuk dapat meningkatkan kualitas pembelajaran dan memberdayakan pelajar. Dalam pendidikan kedokteran peer assessment telah lama diperkenalkan dengan penggunaan instrumen yang dikembangkan guna menilai kisaran luas perilaku profesional yang diharapkan. ${ }^{7}$ Menurut Dannefer dkk.,7 peer assessment merupakan metode yang reliabel dan valid dalam hal penilaian dimensi kognitif dan humanistik, sedangkan Linn dkk. menyatakan bahwa peer assessment meliputi penilaian tentang aspek kognitif, relationship, dan kerja sama dalam tim.
Hasil penelitian mengenai peer assessment mahasiswatingkat 2(dua) dantingkat 4 (empat) FK Unisba pada tahun akademik 2012/2013 juga memperlihatkan bahwa sebagian besar mahasiswa mempunyai nilai peer assessment yang baik, sebagian kecil kategorinya cukup, dan tidak ada seorangpun yang mempunyai nilai buruk. Hasil ini menggambarkan bahwa penilaian mahasiswa lain terhadap teman dalam kelompoknya cukup baik karena peer assessment harus dilaksanakan dalam konteks memberi masukan atau kritikan yang bersifat membangun untuk kemajuan proses belajar dan pembelajaran mahasiswa.?

Peer assessment dapat dipergunakan oleh mahasiswa dalam mengembangkan kemampuan kerja sama, mengkritisi proses dan hasil belajar mahasiswa lain, serta menerima feedback dari orang lain.12 Pada satu sisi, peer assessment juga merupakan bagian dari proses penilaian formal bagi mahasiswa yang mencakup sharing peer feedback dengan mahasiswa. Mahasiswa menganggap bahwa feedback yang diterima dalam peer feedback lebih bermakna daripada feedback yang mereka peroleh dari fakultas. Peer assessment memberikan kontribusi yang besar dalam upaya mengembangkan proses belajar serta perubahan perilaku dan sikap mahasiswa yang dinilai. ${ }^{7}$ Hasil ini sejalan dengan penelitian Dannefer dkk. ${ }^{7}$ mengenai peer assessment of professional competence yang memperlihatkan peer assessment mampu melihat kemampuan bekerja sama dan kemampuan interpersonal.

Uji korelasi self assessment dengan peer assessment pada mahasiswa tingkat dua dan mahasiswa tingkat empat mempunyai korelasi yang bermakna positif, hal ini berarti nilai self assessment yang baik akan berkorelasi dengan nilai peer assessment yang baik pula. Hal ini menggambarkan bahwa mahasiswa berada dalam satu komunitas yang baik mampu membangun kerja sama yang baik dikarenakan penilaian self assessment sejalan dengan penilaian peer assessment. Pada hasil penelitian terlihat bahwa pada umumnya kategori self assessment sesuai 
dengan kategori peer assessment, walaupun terdapat sebagian kecil dari mahasiswa yang penilaian kategori selfassessment-nya lebih kecil dibanding dengan penilaian peer assessment (underestimate), sebagian kecil lainnya menilai dirinya lebih tinggi dibanding dengan penilaian teman-temannya (overestimate).

Korelasi self assessment dan peer assessment dengan nilai kelulusan OSCE pada mahasiswa tingkat dua menunjukkan hasil yang bermakna, sedangkan mahasiswa tingkat empat hanya self assessment menunjukkan hasil yang bermakna, tetapi peer assessment-nya tidak menghasilkan perbedaan yang bermakna. Self assessment yang mempunyai korelasi dengan nilaikelulusan OSCE menggambarkan bahwa para mahasiswa menilai secara keseluruhan bahwa mereka mempunyai kesiapan yang baik dalam menghadapi OSCE dan mampu mengikuti OSCE dengan baik. Hal ini terbukti dengan nilai kelulusan OSCE yang semakin baik pula. Keadaan ini sesuai dengan penelitian Pieree dkk. ${ }^{6}$ mengenai student selfassessment in a paediatric objective structured clinical examination yang menunjukkan bahwa terdapat korelasi bermakna positif penilaian self assessment dengan hasil OSCE.

\section{Simpulan}

Selfassessment mempunyai korelasi yang positif terhadap nilai kelulusan OSCE pada mahasiswa tingkat dua dan juga tingkat empat FK Unisba tahun akademik 2012/2013. Peer assessment mempunyai korelasi yang positif terhadap nilai kelulusan OSCE pada mahasiswa tingkat dua FK Unisba. Self assessment mempunyai korelasi yang positif terhadap peer assessment pada mahasiswa tingkat dua dan tingkat empat FK Unisba.

\section{Ucapan Terima Kasih}

Ucapan terima kasih dan penghargaan penulis berikan kepada pimpinan Fakultas Kedokteran Universitas Islam Bandung dan unit assessment yang terkait.

\section{Daftar Pustaka}

1. Departemen Pendidikan Nasional. Kurikulum berbasis kompetensi. Pelayanan profesional kurikulum. Jakarta: Departemen Pendidikan Nasional; 2004.

2. Konsil Kedokteran Indonesia. Standar kompetensi dokter Indonesia. Jakarta: Konsil Kedokteran Indonesia; 2006.

3. Masic I, Ciric D, Pulja A, Kulasin I, Pandza H. Quality assessment of medical education and use of information technology. Stud Health Technol Inform. 2009;150:898-902.

4. Page G. Handbook on competency-based assessment in Indonesian medical schools. Vancouver, Canada: University of British Columbia; 2007.

5. Epstein RM. Assessment in medical education. N Engl J Med. 2007;356(4):38796.

6. Pierre RB, Wierenga A, Barton M, Thame K, Branday JM, Christie CD. Student self assessment in a paediatric objective structured clinical examination.West Indian Med J. 2005;54(2):144-8.

7. Dannefer EF, Henson LC, Bierer SB, GradyWeliky TA, Meldrum S, Nofziger AC, dkk. Peer assessment of professional competence. Med Educ. 2005;39(7):713-22.

8. Gibbs G, Simpson C. Condition under which assessment support students learning. LATHE (Internet). 2005 [diunduh 1 April 2011];1;3-31. Tersedia dari: http://eprints. glos.ac.uk/3609.

9. Epstein RM, Hundert EM. Defining and assessing professional competence. JAMA. 2002;287(2):226-35.

10. Davis CW, Allen DO. Assessment in medical pharmacology: designing MCQs to assess a student's type-1 problem-solving skills. Pharmacologist. 1999;41(3):107-11.

11. McGaghie WC, Miller GE, Sajid AW, Telder TV. Competency-based curriculum development in medical education: an introduction. Public Health Pap. 1978;(68): 11-91.

12. Zulharman. Self dan peer assessment sebagai penilaian formatif dan sumatif. 29 Mei 2007 [diunduh 1 April 2011]. Tersedia dari: https://zulharman79. wordpress.com/2007/05/29/self-dan-peerassessment-sebagai-penilaian-formatif-dansumatif. 